\title{
A treelet transform analysis to relate nutrient patterns to the risk of hormonal receptor-defined breast cancer in the European Prospective Investigation into Cancer and Nutrition (EPIC)
}

\author{
Nada Assi ${ }^{1,2}$, Aurelie Moskal ${ }^{1}$, Nadia Slimani ${ }^{1}$, Vivian Viallon $3,4,5$, Veronique Chajes ${ }^{1}$,
} Heinz Freisling ${ }^{1}$, Stefano Monni ${ }^{6}$, Sven Knueppel ${ }^{7}$, Jana Förster ${ }^{7}$, Elisabete Weiderpass $8,9,10,11$, Leila Lujan-Barroso ${ }^{12}$, Pilar Amiano ${ }^{13,14}$, Eva Ardanaz ${ }^{13,15}$, Esther Molina-Montes ${ }^{13,16}$, Diego Salmerón 13,17,18, José Ramón Quirós ${ }^{19}$, Anja Olsen ${ }^{20}$, Anne Tiønneland ${ }^{20}$, Christina C Dahm ${ }^{21}$, Kim Overvad ${ }^{21}$, Laure Dossus 22,23,24 , Ágnès Fournier ${ }^{22,23,24}$, Laura Baglietto ${ }^{25,26}$, Renee Turzanski Fortner6 , Rudolf Kaaks ${ }^{6}$, Antonia Trichopoulou 27,28, Christina Bamia ${ }^{29}$, Philippos Orfanos ${ }^{29}$, Maria Santucci De Magistris ${ }^{30}$, Giovanna Masala ${ }^{31}$, Claudia Agnoli ${ }^{32}$, Fulvio Ricceri ${ }^{33}$, Rosario Tumino ${ }^{34}$, H Bas Bueno de Mesquita ${ }^{35,36,37}$, Marije F Bakker ${ }^{38}$, Petra HM Peeters ${ }^{38}$, Guri Skeie ${ }^{8}$, Tonje Braaten ${ }^{8}$, Anna Winkvist ${ }^{39}$, Ingegerd Johansson ${ }^{40}$, Kay-Tee Khaw ${ }^{41}$, Nicholas J Wareham ${ }^{42}$, Tim Key ${ }^{43}$, Ruth Travis ${ }^{43}$, Julie A Schmidt ${ }^{43}$, Melissa A Merritt ${ }^{37}$, Elio Riboli ${ }^{37}$, Isabelle Romieu ${ }^{1}$ and Pietro Ferrari ${ }^{1, *}$ ${ }^{1}$ International Agency for Research on Cancer, 150 Cours Albert Thomas, 69372 Lyon Cedex 08, France: ${ }^{2}$ Université Claude-Bernard Lyon 1, Villeurbanne, France: ${ }^{3}$ Université de Lyon, Lyon, France: ${ }^{4}$ Université Lyon 1, UMRESTTE, Lyon, France: ${ }^{5}$ IFSTTAR, UMRESTTE, Bron, France: ${ }^{6}$ Division of Cancer Epidemiology, German Cancer Research Center (DKFZ), Heidelberg, Germany: ${ }^{7}$ Department of Epidemiology, German Institute of Human Nutrition Potsdam-

Rehbruecke, Nuthetal, Germany: ${ }^{8}$ Department of Community Medicine, Faculty of Health Sciences, University of Tromsø, The Arctic University of Norway, Tromsø, Norway: ${ }^{9}$ Department of Medical Epidemiology and Biostatistics, Karolinska Institutet, Stockholm, Sweden: ${ }^{10}$ Cancer Registry of Norway, Oslo, Norway: ${ }^{11}$ Department of Genetic Epidemiology, Folkhälsan Research Center, Helsinki, Finland: ${ }^{12}$ Unit of Nutrition, Environment and Cancer, Cancer Epidemiology Research Program, Catalan Institute of Oncology (ICO), Bellvitge Biomedical Research Institute (IDIBELL), Barcelona, Spain: ${ }^{13}$ CIBER de Epidemiología y Salud Pública (CIBERESP), Madrid, Spain: ${ }^{14}$ Public Health Division of Gipuzkoa, BioDonostia Research Institute, Health Department, San Sebastian, Spain: ${ }^{15}$ Navarre Public Health Institute, Pamplona, Spain: ${ }^{16}$ Escuela Andaluza de Salud Pública, Instituto de Investigación Biosanitaria de Granada (Granada.ibs), Granada, Spain: ${ }^{17}$ Department of Epidemiology, Murcia Regional Health Council, Murcia, Spain: ${ }^{18}$ Department of Health and Social Sciences, Universidad de Murcia, Murcia, Spain: ${ }^{19}$ Public Health Directorate, Asturias, Oviedo, Spain: ${ }^{20}$ Danish Cancer Society Research Center, Copenhagen, Denmark: ${ }^{21}$ Section for Epidemiology, Department of Public Health, Aarhus University, Aarhus, Denmark: ${ }^{22}$ Inserm, Centre for Research in Epidemiology and Population Health (CESP), Nutrition, Hormones and Women's Health Team, Villejuif, France: ${ }^{23}$ Université Paris Sud, UMRS, Villejuif, France: ${ }^{24}$ IGR, Villejuif, France: ${ }^{25}$ Cancer Epidemiology Centre, Cancer Council of Victoria, Melbourne, Australia: ${ }^{26}$ Centre for Epidemiology and Biostatistics, School of Population and Global Health, University of Melbourne, Melbourne, Australia: ${ }^{27}$ Hellenic Health Foundation, Athens, Greece: ${ }^{28}$ Bureau of Epidemiologic Research, Academy of Athens, Athens, Greece: ${ }^{29}$ Department of Hygiene, Epidemiology and Medical Statistics, University of Athens Medical School, Athens, Greece: ${ }^{30}$ Azienda Ospedaliera Universitaria (AOU) Federico II, Naples, Italy: ${ }^{31}$ Molecular and Nutritional Epidemiology Unit, Cancer Research and Prevention Institute - ISPO, Florence, Italy: ${ }^{32}$ Epidemiology and Prevention Unit, Fondazione IRCCS, Istituto Nazionale dei Tumori, Milan, Italy: ${ }^{33}$ Unit of Cancer Epidemiology CERMS, Department of Medical Sciences, University of Turin and Città della Salute e della Scienza Hospital, Turin, Italy: ${ }^{34}$ Cancer Registry and Histopathology Unit, 'Civile M.P. Arezzo' Hospital, Ragusa, Italy: ${ }^{35}$ Department for Determinants of Chronic Diseases (DCD), National Institute for Public Health and the Environment (RIVM), Bilthoven, The Netherlands: ${ }^{36}$ Department of Gastroenterology and Hepatology, University Medical Centre, Utrecht, The Netherlands: ${ }^{37}$ Department of Epidemiology and Biostatistics, The School of Public Health, Imperial College London, London, UK: ${ }^{38}$ Department of Epidemiology, Julius Center for Health Sciences and Primary Care, University Medical Center Utrecht, Utrecht, The Netherlands: ${ }^{39}$ Department of Internal Medicine and Clinical Nutrition, The Sahlgrenska Academy, Göteborg, Sweden: ${ }^{40}$ Department of Odontology, Umeå University, Umeå, Sweden: ${ }^{41}$ Department of Public Health and Primary Care, University of Cambridge School of Clinical Medicine, Cambridge, UK: ${ }^{42}$ MRC Epidemiology Unit, University of Cambridge School of Clinical Medicine, Cambridge, UK: ${ }^{43}$ Cancer Epidemiology Unit, Nuffield Department of Population Health, University of Oxford, Oxford, UK 


\section{Abstract}

Objective: Pattern analysis has emerged as a tool to depict the role of multiple nutrients/foods in relation to health outcomes. The present study aimed at extracting nutrient patterns with respect to breast cancer (BC) aetiology.

Design: Nutrient patterns were derived with treelet transform (TT) and related to $\mathrm{BC}$ risk. TT was applied to twenty-three log-transformed nutrient densities from dietary questionnaires. Hazard ratios (HR) and 95\% confidence intervals computed using Cox proportional hazards models quantified the association between quintiles of nutrient pattern scores and risk of overall BC, and by hormonal receptor and menopausal status. Principal component analysis was applied for comparison.

Setting: The European Prospective Investigation into Cancer and Nutrition (EPIC). Subjects: Women ( $n$ 334 850) from the EPIC study.

Results: The first TT component (TC1) highlighted a pattern rich in nutrients found in animal foods loading on cholesterol, protein, retinol, vitamins $\mathrm{B}_{12}$ and $\mathrm{D}$, while the second TT component (TC2) reflected a diet rich in $\beta$-carotene, riboflavin, thiamin, vitamins $\mathrm{C}$ and $\mathrm{B}_{6}$, fibre, $\mathrm{Fe}, \mathrm{Ca}, \mathrm{K}, \mathrm{Mg}, \mathrm{P}$ and folate. While TC1 was not associated with $\mathrm{BC}$ risk, TC2 was inversely associated with $\mathrm{BC}$ risk overall $\left(\mathrm{HR}_{\mathrm{Q} 5} v \cdot \mathrm{Q} 1=0.89,95 \% \mathrm{CI} 0.83,0.95, P_{\text {trend }}<0.01\right)$ and showed a significantly lower risk in oestrogen receptor-positive $\left(\mathrm{HR}_{\mathrm{Q} 5} v . \mathrm{Q} 1=0 \cdot 89,95 \%\right.$ CI $0 \cdot 81,0.98$, $\left.P_{\text {trend }}=0 \cdot 02\right)$ and progesterone receptor-positive tumours $\left(\mathrm{HR}_{\mathrm{Q} 5} v \cdot \mathrm{Q} 1=0 \cdot 87,95 \%\right.$ CI $\left.0.77,0.98, P_{\text {trend }}<0 \cdot 01\right)$.

Conclusions: TT produces readily interpretable sparse components explaining similar amounts of variation as principal component analysis. Our results suggest that participants with a nutrient pattern high in micronutrients found in vegetables, fruits and cereals had a lower risk of BC.

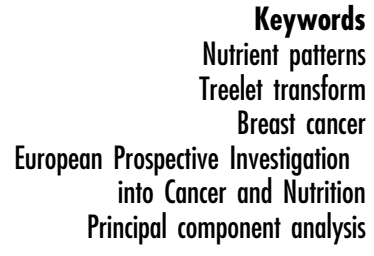

Breast cancer (BC) remains the highest incident cancer affecting women worldwide, with almost 1670000 cases registered in 2012. It is a major public health concern with mortality from BC accounting for over 522000 deaths in 2012, including almost 198000 deaths in Western countries and about 324000 in less developed regions ${ }^{(1)}$. Established BC risk factors include age, genetic mutations, ethnicity, height, reproductive history, breast-feeding, hormone therapy and diabetes ${ }^{(2-6)}$. Besides these, a number of modifiable lifestyle factors are associated with BC such as smoking ${ }^{(7,8)}$, body fat and obesity ${ }^{(9-11)}$, physical inactivity ${ }^{(10,12,13)}$, alcohol consumption ${ }^{(14-16)}$ and $\operatorname{diet}^{(5,17,18)}$. Diet has been suggested to account for up to $25-40 \%$ of preventable causes of cancers; in particular, $50 \%$ of $\mathrm{BC}$ deaths are linked to diet, although the consensus around this estimate is not unanimous ${ }^{(12,19,20)}$. Standard approaches customarily evaluate the risk of BC associated with one or a group of dietary items, i.e. food(s) or nutrient(s). Nevertheless, associations between diet and disease might be missed when one parses the effect of a limited list of dietary constituents. Although this simplified approach of examining a single food or nutrient at a time has led to important results on the role of an individual dietary component in BC aetiology, such as fibre from vegetables, alcohol, tea consumption, folate and other micronutrients ${ }^{(12,14,18,20-23)}$, research might benefit from a more comprehensive approach by exploring BC aetiology in terms of an integrated ensemble of dietary characteristics.
To capture the complexity of individuals' dietary habits, dietary pattern analysis has emerged as a complementary holistic methodology focusing on sets of dietary variables and addressing their inherent interrelations ${ }^{(24)}$. This approach is justified as components of dietary exposure are not independent ${ }^{(25,26)}$ and because it allows to account for complex relationships between nutrients in biological pathways $^{(25)}$. In addition, BC is a multifactorial disease ${ }^{(2-18)}$, the aetiology of which possibly depends on more than a restricted list of dietary items.

Recent investigations carried out in Western populations ${ }^{(27-32)}$ have consistently identified two main dietary patterns: the prudent/healthy and the Western/unhealthy ${ }^{(29,33)}$. While diet is related to cultural background, common nutrients are present in different combinations of foods; hence looking into diet-disease associations on the nutrient scale could lead to the identification of specific nutritional profiles relevant to $\mathrm{BC}$ aetiology.

In the present study, nutrient patterns within the European Investigation into Cancer and Nutrition (EPIC) were related to BC risk. Nutrient patterns were obtained by applying the treelet transform (TT) that has recently been introduced into nutritional epidemiology ${ }^{(34-36)}$ and the wellknown principal component analysis (PCA) was used for the sake of comparison ${ }^{(37)}$. TT yields sparse components and reveals the intrinsic structure of the data, thus simplifying interpretability. Aspects related to the application of TT to dietary data in the context of a multi-centre study are described and discussed. The association between nutrient 
patterns and $\mathrm{BC}$ was evaluated using all $\mathrm{BC}$ cases and by taking into account the heterogeneity of BC subtypes by integrating information on menopausal and hormone receptor status.

\section{Materials and methods}

\section{Study population and exclusion criteria}

EPIC is a large prospective cohort of 521330 healthy men and women designed to evaluate the relationships between dietary habits, nutrition, lifestyle factors and the incidence of cancer. The EPIC cohort includes participants from twentythree centres in France, Germany, Denmark, Sweden, Norway, Greece, Italy, the Netherlands, Spain and the UK. In most centres, participants were recruited from the general population, the exceptions being France (women were enrolled from a national health insurance scheme covering teachers in the French education system employees), Italy (Turin and Ragusa: blood donors; Florence: screening programme participants), Spain (blood donors) and the Netherlands (Utrecht: women participating in BC screening). In Norway, only women from the general population were recruited and in the UK, one-half of the cohort (the Oxford sub-cohort) consisted of 'health-conscious' individuals from England, Wales, Scotland and Northern Ireland. The design of the study and its rationale along with the recruitment process have been described elsewhere ${ }^{(38)}$.

Among the 521330 EPIC participants, men were first removed ( $n$ 153 427). Women with prevalent cancers at any site at baseline (other than non-melanoma skin cancer; $n$ 19 853) or lost to follow-up ( $n$ 2892) were excluded, as were women who did not complete any dietary questionnaire ( $n$ 3315) and those who did not complete a lifestyle questionnaire ( $n$ 26). To avoid including extreme values, participants in the top and bottom $1 \%$ of the distribution of the ratio of reported total energy intake to energy requirement ( $n$ 6753) were excluded. After exclusion of non-first BC cases ( $n$ 2) the cohort included 335062 women upon whom the dietary patterns were derived. An additional number of women ( $n$ 212) with missing information on BC status were excluded, which left 334850 women retained for the statistical analyses.

\section{Cancer assessment}

Incident BC cases were identified through population cancer registries (Denmark, Italy, Netherlands, Norway, Spain, Sweden and UK) or through active follow-up (France, Germany, Naples and Greece), as detailed in Ferrari et $a l .{ }^{(21)}$. Information on oestrogen receptor (ER) and progesterone receptor (PR) statuses was provided by each centre on the basis of pathology reports.

\section{Dietary assessment}

Long-term usual dietary intake was assessed at baseline using country-specific and validated dietary questionnaires (self-administered FFQ, semi-quantitative or interviewerperformed $)^{(38-40)}$. In the validation studies, the dietary questionnaires were compared with a reference method which was in most centres $24 \mathrm{~h}$ dietary recalls, except in Sweden and the UK, where food records were used. Generally, the correlation coefficients were between 0.40 and 0.70 for all nutrients examined which was considered satisfactory $^{(41)}$. Individual intakes of twenty-three nutrients and total energy were estimated using a common food composition database, the EPIC Nutrient Database (ENDB), which was compiled from national food composition databases of the ten countries represented in EPIC following standardized procedures ${ }^{(42,43)}$.

\section{Lifestyle questionnaires}

Information on sociodemographic characteristics, including education, and lifestyle habits such as levels of physical activity, tobacco smoking, as well as consumption of alcohol and drinking habits, were collected using lifestyle questionnaires. In addition, anthropometric measures and past medical information were gathered at recruitment ${ }^{(38)}$.

\section{Nutrient pattern assessment}

EPIC-wide nutrient patterns were derived among female participants in EPIC using TT in the main analysis and PCA in the sensitivity analysis. The sample covariance matrix of twenty-three log-transformed nutrient densities, computed using alcohol-free energy intake ${ }^{(44)}$, was consistently used. The use of the sample covariance matrix allows variability to be informative in the pattern discovery phase. The distribution of nutrient consumption tends to be lognormal and may not be best described by the mean and variance on the original scale. Moreover micro- and macronutrients are expressed on different scales (micrograms, milligrams or grams). The nutrient densities were log-transformed to remove scale dependence and render their variance (or covariance) independent of the unit of measure. In line with previous work $^{(28,45,46)}$, alcohol intake was not included and was considered as a lifestyle factor. Total fat was divided into MUFA, PUFA and SFA, and total carbohydrates were broken down into starch and sugar. The micro- and macronutrients studied were Ca, $\beta$-carotene, cholesterol, MUFA, PUFA, SFA, Fe, fibre, K, $\mathrm{Mg}, \mathrm{P}$, protein, retinol, riboflavin, starch, sugar, thiamin, vitamins $\mathrm{B}_{6}, \mathrm{~B}_{12}, \mathrm{C}, \mathrm{D}, \mathrm{E}$ and folate. The list of nutrients as well as the approach described for their handling is consistent with the nutrient patterns initiative within EPIC described by Moskal et al. ${ }^{(45)}$.

\section{Pattern extraction}

The TT method used for pattern extraction is described in detail by Gorst-Rasmussen and co-workers ${ }^{(35,47)}$. Briefly, TT is a dimension reduction technique aimed at converting a set of observations of possibly correlated variables into orthogonal components. TT scores, corresponding to 
the projection of data onto components, generally have a small degree of correlation, unlike PCA scores that are always uncorrelated. The number of retained components was based on the percentage of explained variance, scree plots and interpretability. The nutrient patterns were defined after the inspection of factor loadings, i.e. eigenvectors, expressing the contribution of nutrients to a given component. Score variables were determined for each component of TT and reflected adherence to a given type of diet/nutrient profile. TT combines the quantitative pattern extraction capabilities of PCA with interpretational advantages of hierarchical clustering of variables. In TT, the two variables displaying the highest correlation (or covariance) are identified, and a PCA is performed on them. The two variables are then replaced with the score of their first PCA component and a merge is indicated in

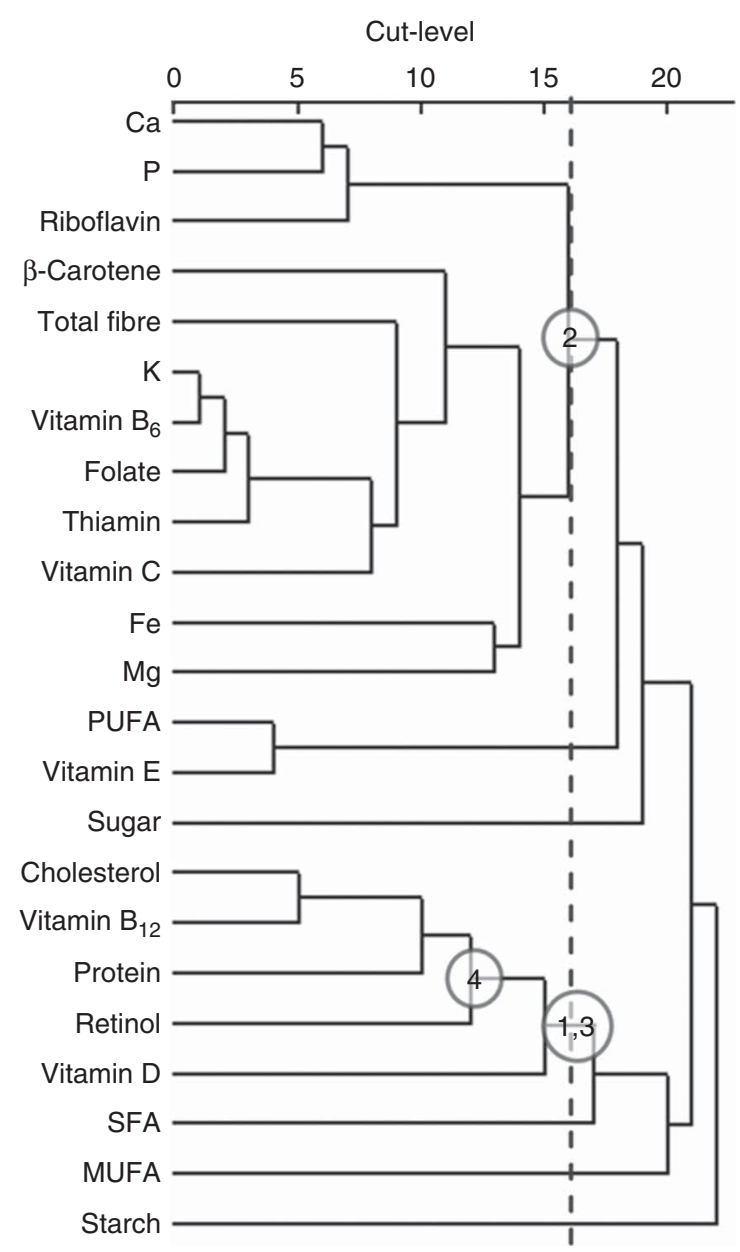

Fig. 1 Cluster tree produced by the treelet transform algorithm applied to twenty-three log-transformed nutrient densities for 335062 women in the European Prospective Investigation into Cancer and Nutrition (EPIC). The dashed line indicates the chosen cut-level (16) to extract components. The highestvariance factors, i.e. treelet components at this level of the tree, are indicated with numbered circles. The nutrients related to these nodes have non-zero loadings on the given component. Components 1 and 3 share the same node but the variable loadings differ the cluster tree. This operation is re-iterated until all variables have joined the cluster tree. In this way, TT produces a hierarchical grouping of variables which may reveal intrinsic characteristics of data structure. An important feature of TT is that it introduces sparsity into factors, making many factors loadings exactly equal to zero, potentially simplifying the interpretation. Alongside the cluster tree dendrogram produced by TT (as exemplified in Fig. 1), TT yields a coordinate system for the data at each level of the cluster tree. Selecting a cluster tree level (cut-level) for the TT cluster tree amounts to choosing the level of detail desired in the dimension reduction of data. More variation can be explained at the cost of factor sparsity when the cluster tree is cut near its 'root'. If the data have $p$ variables, there are $p-1$ possible cut-levels. After deciding on the number of components to retain, we performed a tenfold cross-validation to identify the optimal cut-level, i.e. the point at which increasing the cutlevel does not substantially increase the variation of the retained patterns. We also performed a sensitivity analysis to assess the effect of different cut-levels ${ }^{(35,48)}$.

Consistently, a PCA was also applied for the sake of comparison $^{(37)}$. This technique yields orthogonal components that are invariant to the number of subsequent components retained. PCA identifies the best linear combination of the variables accounting for the most variance observed in the original data, producing components with uncorrelated scores. Results of TT analysis were compared with findings obtained with the more classic PCA method. To make the comparison easier, and because TT returns sparse vectors, only nutrients with absolute loadings greater than $0 \cdot 2$ were retained to identify a given pattern in PCA.

\section{Patterns and breast cancer risk}

The associations between nutrient patterns and risk of $\mathrm{BC}$ were investigated by using Cox proportional hazards regression models to estimate hazard ratios (HR) and 95\% confidence intervals. Breslow's method was adopted for handling time ties ${ }^{(49)}$. The time at entry was the age at recruitment and the time of exit was the age at cancer diagnosis, death, loss or end of follow-up, whichever happened first. Models were stratified by centre, to control for differences in questionnaire designs, follow-up procedures and other centre-specific effects, as well as for age at recruitment (1-year categories) ${ }^{(50)}$. Analyses were performed by considering the TT (and principal component (PC)) scores in quintiles to appreciate potential departure from linearity. Statistical analyses were adjusted for baseline menopausal status (premenopausal and perimenopausal (reference) or postmenopausal and women who underwent an ovariectomy), baseline alcohol intake (never drinkers (reference), former drinkers, drinkers only at recruitment, lifetime drinkers, unknown), height (continuous), BMI (below (reference) or above $25 \mathrm{~kg} / \mathrm{m}^{2}$ ), schooling level (none, primary (reference), technical/ 
professional/secondary, longer education, unknown/ unspecified), age at first full-term pregnancy (nulliparous (reference), $\leq 21$ years, $21-30$ years, $>30$ years, unknown or missing), age at menarche ( $\leq 12$ years (reference), $12-14$ years, $>14$ years, missing), age at menopause $(\leq 50$ years (reference), $>50$ years, premenopausal or missing), use of hormone replacement therapy (never (reference), ever, unknown), level of physical activity (categorical, metabolic equivalents of task (MET)/h: inactive (reference), moderately inactive, moderately active, active, unknown) and alcohol-free energy (continuous). Use of oral contraceptive pills (never (reference), ever or unknown) and smoking status (never smokers (reference), ex-smokers, current smokers, unknown) were evaluated but not retained in the final models, due to limiting confounding exerted by these variables.

The overall significance of a score variable in categories was evaluated using the likelihood ratio test statistics $\left(P_{\mathrm{LRT}}\right)$ with $\mathrm{df}=4$. Additionally, $P$ values for trend $\left(P_{\text {trend }}\right)$ were computed by modelling a score variable with quintile-specific medians as continuous. The association between nutrient patterns and BC risk was evaluated in pre- and postmenopausal women and according to $\mathrm{BC}$ hormonal receptor status (ER/PR status). Interaction between menopausal status and pattern scores was explored. In addition, tests of heterogeneity of associations according to receptor status were performed using the data-augmentation method ${ }^{(51)}$ by comparing the difference in the log likelihood between a model with receptor status-specific variable and a model with a single HR estimate for the two categories of receptor status to a $\chi^{2}$ distribution with $\mathrm{df}=1$ ( $\left(P_{\text {heterogeneity }}\right)$.

Departure from linearity was explored with restricted cubic splines ${ }^{(52)}$, using five knots corresponding to the 1 st and 99th percentiles and medians of the centred scores of quintiles 1, 3 and 5. Spline plots were produced by taking the median of the first quintile as reference. Departures from linearity were assessed via an evaluation of the joint significance of variables other than the linear one included in the model using Wald's test on $\mathrm{df}=3$. Associations between all of the PC and BC were investigated in a consistent way.

Statistical tests were two-sided, the per-test significance level was set to $\alpha=0 \cdot 05$. All analyses were performed using the SAS statistical software package version $9 \cdot 3$; the ' $t$ ' package in the STATA statistical software package release 12 was used to perform TT.

\section{Results}

A total of $11576 \mathrm{BC}$ cases were recorded in 11.5 years of median follow-up time and 3670439 person-years. Based on the information obtained at baseline, 2827 cases were premenopausal, 5872 were postmenopausal, 2548 were perimenopausal and 328 cases had a bilateral ovariectomy. Among incident cases, information on hormone receptor status for ER and PR was available only in $62 \%$ and $52 \%$ of total cancer cases, respectively, and was distributed as follows: $81 \% \mathrm{ER}^{+}$and $19 \% \mathrm{ER}^{-}$tumours and $63 \% \mathrm{PR}^{+}$and $37 \% \mathrm{PR}^{-}$tumours. Descriptive information of the study sample by EPIC country is available in Table 1.

\section{Identification of nutrient patterns}

Inspection of factor loadings allowed an initial identification of four nutrient patterns with TT, explaining $62 \%$ of total nutrient intake variability within individuals. After a tenfold cross-validation along with a sensitivity analysis strategy and after evaluating the interpretability of each pattern, we chose to cut the cluster tree at level 16. Loadings of components 1 and 2 are shown in Table 2. TT yielded a dendrogram shown in Fig. 1, with numbered nodes indicating the four highest-variance factors, where factors 1 and 2 were identified as the first two components after setting the cut-level to 16 indicated by the dashed line. This dendrogram reveals the correlation structure of the log-transformed nutrient densities. The first treelet component (TC1) loaded on vitamin $\mathrm{D}$, vitamin $\mathrm{B}_{12}$, cholesterol, protein and retinol, suggesting a diet rich in animal products. The second treelet component (TC2)

Table 1 Numbers of women and breast cancer (BC) cases (first tumours only) in the European Prospective Investigation into Cancer and Nutrition (EPIC) cohort by country

\begin{tabular}{|c|c|c|c|c|c|}
\hline Country & No. of women & Person-years & No. of BC cases & Follow-up time (years)* & Age at enrolment (years) ${ }^{\star}$ \\
\hline France & 67356 & 699216 & 3187 & $11 \cdot 8$ & 51.5 \\
\hline Italy & 30498 & 341417 & 1047 & $11 \cdot 7$ & $50 \cdot 9$ \\
\hline Spain & 24846 & 299575 & 495 & $12 \cdot 6$ & $47 \cdot 7$ \\
\hline UK general population & 17145 & 200812 & 719 & $12 \cdot 3$ & $55 \cdot 6$ \\
\hline UK health-conscious & 35368 & 385353 & 761 & $11 \cdot 3$ & 41.5 \\
\hline Netherlands & 26839 & 315554 & 916 & $12 \cdot 2$ & $52 \cdot 7$ \\
\hline Greece & 15224 & 148594 & 198 & $10 \cdot 7$ & $53 \cdot 6$ \\
\hline Germany & 27390 & 272011 & 834 & $10 \cdot 9$ & $48 \cdot 4$ \\
\hline Sweden & 26339 & 349110 & 1095 & 13.9 & $50 \cdot 6$ \\
\hline Denmark & 28693 & 316601 & 1340 & $11 \cdot 6$ & $56 \cdot 3$ \\
\hline Norway & 35152 & 342195 & 984 & $10 \cdot 1$ & $48 \cdot 0$ \\
\hline Total & 334850 & 3670439 & 11576 & 11.5 & 51.0 \\
\hline
\end{tabular}

*Median is given for follow-up time and age at enrolment. 
Table 2 Loadings of the first two components from treelet transform (TT; cut-level 16)

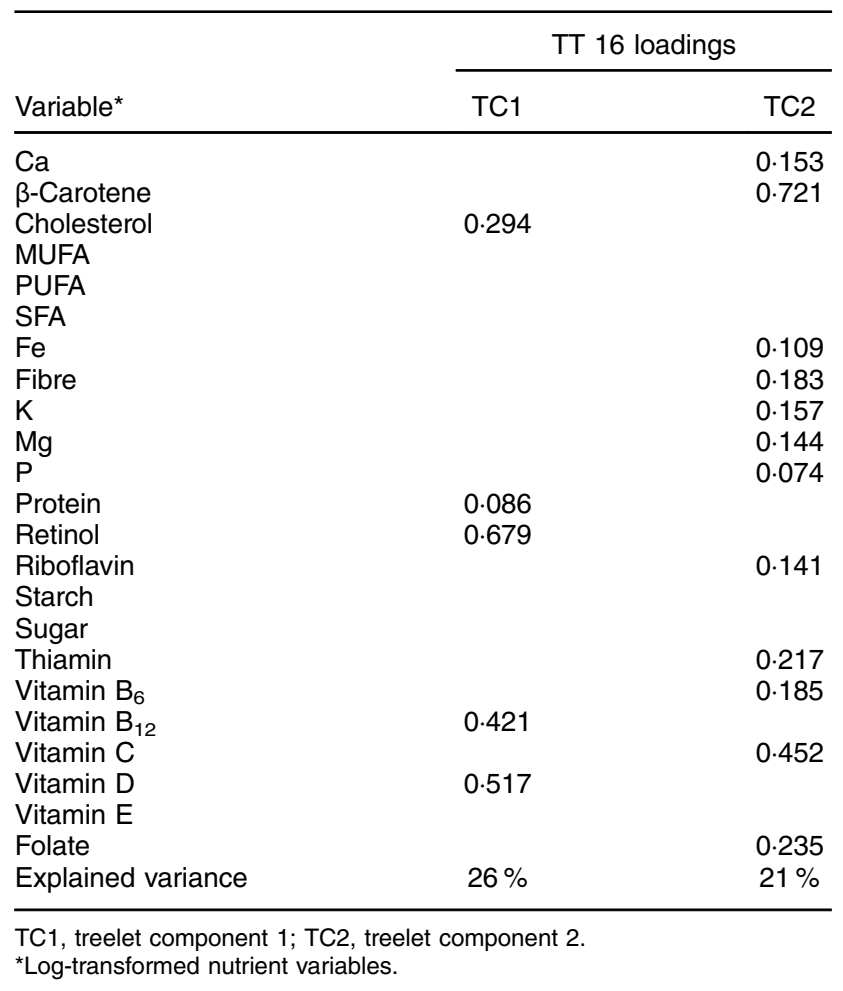

presented high positive loadings on $\beta$-carotene, thiamin, fibre, vitamin $\mathrm{C}$ and folate, and singled out some nutrients with mild loadings $(<0 \cdot 2)$, i.e. $\mathrm{Fe}, \mathrm{Ca}, \mathrm{K}, \mathrm{Mg}$ and $\mathrm{P}$ (Table 2). TC2 may evoke a diet rich in vegetables, fruits and cereals. While the third treelet component (TC3) was largely driven by vitamin $\mathrm{D}$, the fourth treelet component (TC4) was less straightforward to characterize, as displayed in the online supplementary material, Supplemental Table 1. Distributions of known risk factors for BC by quintiles of TT scores for the first two components are displayed in Table 3.

PC loadings are displayed in the online supplementary material, Supplemental Table 2. PCA produced patterns similar to TT with respect to the amount of variability explained and the nutrients contributing to the definition of each component: with PC1 displaying high loadings for cholesterol, retinol, vitamin $\mathrm{B}_{12}$ and vitamin $\mathrm{D}$ and negative loadings for vitamin $\mathrm{C}$ and $\beta$-carotene; and PC2 suggesting a micronutrient-dense pattern rich in fruits, vegetables, plant foods and dairy. The first two components (in TT and PCA) explained the most variability and were the most informative with respect to capturing meaningful nutrient patterns, and thus were further related to $\mathrm{BC}$ risk in disease models.

\section{Nutrient patterns and breast cancer risk}

Scores of nutrient patterns were related to BC risk. TC1 showed no statistically significant association with $\mathrm{BC}$ risk with $\mathrm{HR}_{\mathrm{TC} 1 \text { Q5 }}$. Q1 $=1.05$ (95\% CI 0.98, 1.13, $P_{\text {trend }}=0.36$,
$P_{\mathrm{LRT}}=0 \cdot 39$ ), while TC2 was significantly associated with $\mathrm{BC}$ risk with $\mathrm{HR}_{\mathrm{TC} 2}$ Q5 $v$. Q1 $=0.89$ (95\% CI $0.83,0.95$, $P_{\text {trend }}<0.001, P_{\mathrm{LRT}}=0.02$ ), as shown in Table 4 . The relationship between TT scores and BC risk was modelled through restricted cubic splines (RCS) and is presented in Fig. 2. Overall, there was a significant progressive decrease in $\mathrm{BC}$ risk for the second component. TC2 scores showed a linear decrease in $\mathrm{BC}$ risk $\left(\mathrm{RCS}_{\mathrm{TC} 2} P_{\text {trend }}=0.02\right)$. However, no departure from linearity was observed $\left(P_{\text {Wald non-linearity }}=0.94\right.$ and 0.77 , respectively, in TC1 and TC2; Fig. 2). Analyses of interaction between TC (or PC) scores and menopausal status were not statistically significant (results not shown).

\section{Hormonal receptor status}

In $\mathrm{ER}^{-}$tumours, no significant association with $\mathrm{BC}$ risk was observed for TC1 and TC2 scores (Table 4). For $\mathrm{ER}^{+}$ tumours there was a decrease in $\mathrm{BC}$ risk in the fourth and fifth quintiles of TC2 scores with $\mathrm{HR}_{\mathrm{Q} 4} v$. Q1 $=0.90(95 \% \mathrm{CI}$ $0.83,0.99$ ) and $\mathrm{HR}_{\mathrm{Q} 5} v . \mathrm{Q}_{1}=0.89$ (95\% CI $0.81,0.98$, $P_{\text {trend }}=0.02$; Table 4). Regarding $\mathrm{PR}^{-}$tumours (see online supplementary material, Supplemental Table 3), the second component TC2 showed a decreased BC risk with $\mathrm{HR}_{\mathrm{Q} 5}$ v. $\mathrm{Q} 1=0.84$ (95\% CI $\left.0.72,0.98\right)$. For $\mathrm{PR}^{+}$tumours, TC2 was linked with a decreased $\mathrm{BC}$ risk in participants in the fifth quintile with $\mathrm{HR}_{\mathrm{Q} 5} v \cdot \mathrm{Q} 1=0.87$ (95\% CI 0.77, 0.98). No significant association was seen for $\mathrm{ER}^{-} / \mathrm{PR}^{-}$tumours (Table 5). TC2 was linked with a decreased $\mathrm{BC}$ risk trend in $\mathrm{ER}^{+} / \mathrm{PR}^{+}$tumours with $\mathrm{HR}_{\mathrm{Q} 5} v \cdot \mathrm{Q}_{1}=0.86(0.76,0.98$, $P_{\text {trend }}<0.01$; Table 5$)$. Tests of heterogeneity yielded no significant results.

PCA derived components displayed a significant increase in $\mathrm{BC}$ risk for $\mathrm{PC} 1$ in participants in the highest quintile and a decreasing trend of $\mathrm{BC}$ risk for $\mathrm{PC} 2$, as shown in the online supplementary material, Supplemental Table 4 and Supplemental Fig. 1. Results of associations of PC with tumours by hormone receptor status are displayed in the online supplementary material, Supplemental Tables 4 and 5 .

\section{Discussion}

In the present study, the role of nutrient patterns in the aetiology of BC was explored through the use of TT, a multivariate method recently introduced to the landscape of nutritional epidemiology ${ }^{(34-36)}$. The association was evaluated in the context of the EPIC study, characterized by large variability of dietary habits and by a large number of incident cancer cases across participating centres ${ }^{(38)}$.

In recent years, dietary pattern analysis has emerged as a promising technique, complementary to methods focusing on individual foods or food components, to investigate the relationships between diet and risk of disease $^{(25)}$. A systematic review and meta-analysis on dietary patterns in $\mathrm{BC}$ aetiology ${ }^{(33)}$ selected eighteen 
Table 3 Lifestyle and dietary baseline characteristics* according to the lowest, middle and highest quintiles of treelet transform (cut-level 16) scores for the first and second components among 334850 women in the European Prospective Investigation into Cancer and Nutrition (EPIC)

\begin{tabular}{|c|c|c|c|c|c|c|c|c|c|c|c|c|}
\hline & \multicolumn{6}{|c|}{ TC1 } & \multicolumn{6}{|c|}{ TC2 } \\
\hline & \multicolumn{2}{|c|}{ Q1 } & \multicolumn{2}{|c|}{ Q3 } & \multicolumn{2}{|c|}{ Q5 } & \multicolumn{2}{|c|}{ Q1 } & \multicolumn{2}{|c|}{ Q3 } & \multicolumn{2}{|c|}{ Q5 } \\
\hline & Mean & SD & Mean & SD & Mean & SD & Mean & SD & Mean & SD & Mean & SD \\
\hline No. of women & \multicolumn{2}{|c|}{66988} & \multicolumn{2}{|c|}{66977} & \multicolumn{2}{|c|}{66955} & \multicolumn{2}{|c|}{66961} & \multicolumn{2}{|c|}{66969} & \multicolumn{2}{|c|}{66970} \\
\hline Age (years) & $50 \cdot 2$ & $11 \cdot 8$ & $50 \cdot 8$ & & $52 \cdot 0$ & $8 \cdot 1$ & 49.6 & $9 \cdot 3$ & $51 \cdot 1$ & 9.5 & $52 \cdot 2$ & $10 \cdot 9$ \\
\hline Weight (kg) & $63 \cdot 0$ & $11 \cdot 6$ & 64.8 & $11 \cdot 8$ & $65 \cdot 0$ & $11 \cdot 9$ & $64 \cdot 0$ & 11.9 & $64 \cdot 0$ & 11.7 & 63.8 & 11.5 \\
\hline Height $(\mathrm{cm})$ & $160 \cdot 1$ & $7 \cdot 1$ & $162 \cdot 6$ & 6.5 & $163 \cdot 0$ & 6.5 & $162 \cdot 0$ & 6.9 & $162 \cdot 5$ & $6 \cdot 7$ & $162 \cdot 0$ & $6 \cdot 5$ \\
\hline Non-alcohol energy $(\mathrm{kJ} / \mathrm{d})$ & 7565 & 2280 & 7573 & 2171 & 7368 & 2121 & 8309 & 2406 & 7623 & 2138 & 6820 & 1929 \\
\hline \multirow[t]{2}{*}{ Non-alcohol energy (kcal/d) } & 1808 & 545 & 1810 & 519 & 1761 & 507 & 1986 & 575 & 1822 & 511 & 1630 & 461 \\
\hline & \multicolumn{2}{|c|}{$\%$} & & $\%$ & & $\%$ & & $\%$ & & $\%$ & & $\%$ \\
\hline BMI class & & & & & & & & & & & & \\
\hline Below $25 \mathrm{~kg} / \mathrm{m}^{2}$ & & 57 & & 59 & & 57 & & 58 & & 58 & & 59 \\
\hline Above $25 \mathrm{~kg} / \mathrm{m}^{2}$ & & 43 & & 41 & & 43 & & 42 & & 42 & & 41 \\
\hline Schooling level & & & & & & & & & & & & \\
\hline None & & 11 & & 3 & & 2 & & 5 & & 5 & & 4 \\
\hline Primary & & 25 & & 22 & & 26 & & 33 & & 23 & & 17 \\
\hline Technical/professional/secondary & & 35 & & 47 & & 50 & & 44 & & 46 & & 44 \\
\hline Longer education & & 25 & & 23 & & 19 & & 16 & & 23 & & 28 \\
\hline Unspecified/unknown & & 4 & & 5 & & 3 & & 2 & & 3 & & 8 \\
\hline Use of hormone replacement therap & & & & & & & & & & & & \\
\hline Never & & 82 & & 68 & & 60 & & 71 & & 68 & & 69 \\
\hline Ever & & 16 & & 25 & & 31 & & 20 & & 25 & & 27 \\
\hline Unknown & & 2 & & 7 & & 9 & & 9 & & 7 & & 4 \\
\hline Age at first term pregnancy & & & & & & & & & & & & \\
\hline Nulliparous & & 21 & & 13 & & 11 & & 13 & & 14 & & 19 \\
\hline$\leq 21$ years & & 16 & & 18 & & 24 & & 20 & & 18 & & 17 \\
\hline $21-30$ years & & 52 & & 56 & & 54 & & 54 & & 56 & & 52 \\
\hline$>30$ years & & 9 & & 9 & & 7 & & 8 & & 8 & & 8 \\
\hline Unknown & & 3 & & 5 & & 4 & & 5 & & 4 & & 5 \\
\hline Age at menarche & & & & & & & & & & & & \\
\hline$\leq 12$ years & & 38 & & 35 & & 33 & & 33 & & 35 & & 39 \\
\hline $12-14$ & & 46 & & 46 & & 47 & & 46 & & 47 & & 45 \\
\hline$>14$ years & & 15 & & 15 & & 17 & & 16 & & 16 & & 14 \\
\hline Unknown & & 1 & & 4 & & 4 & & 5 & & 3 & & 3 \\
\hline Age at menopause & & & & & & & & & & & & \\
\hline$\leq 50$ years & & 19 & & 16 & & 18 & & 17 & & 17 & & 18 \\
\hline$>50$ years & & 19 & & 18 & & 19 & & 16 & & 18 & & 19 \\
\hline Unknown & & 63 & & 66 & & 63 & & 67 & & 65 & & 62 \\
\hline Menopausal status & & & & & & & & & & & & \\
\hline Pre and peri & & 55 & & 55 & & 49 & & 60 & & 53 & & 49 \\
\hline Post and ovariectomy & & 45 & & 45 & & 51 & & 40 & & 47 & & 51 \\
\hline Alcohol drinkers & & & & & & & & & & & & \\
\hline Never & & 16 & & 6 & & 4 & & 8 & & 8 & & 9 \\
\hline Former & & 6 & & 3 & & 2 & & 4 & & 3 & & 4 \\
\hline Only at recruitment & & 17 & & 11 & & 8 & & 6 & & 11 & & 19 \\
\hline Lifetime & & 51 & & 56 & & 46 & & 44 & & 54 & & 57 \\
\hline Unknown & & 10 & & 22 & & 40 & & 38 & & 24 & & 11 \\
\hline Physical activity & & & & & & & & & & & & \\
\hline Inactive & & 31 & & 20 & & 16 & & 25 & & 20 & & 21 \\
\hline Moderately inactive & & 33 & & 33 & & 28 & & 30 & & 31 & & 33 \\
\hline Moderately active & & 21 & & 23 & & 18 & & 18 & & 22 & & 24 \\
\hline Active & & 13 & & 15 & & 12 & & 12 & & 14 & & 17 \\
\hline Unknown & & 2 & & 10 & & 25 & & 15 & & 13 & & 5 \\
\hline
\end{tabular}

TC1, treelet component 1; TC2, treelet component 2; Q1, quintile 1; Q3, quintile 3; Q5, quintile 5.

*Means and standard deviations are presented for continuous variables, and frequencies are presented for categorical variables.

relevant studies from case-control and cohort studies that used combinations of foods and micronutrients to identify dietary patterns ${ }^{(17,27,53-66)}$. Two a posteriori defined patterns emerged consistently: the Western/unhealthy (in seventeen studies) and the prudent/healthy (eighteen studies $)^{(33)}$. In the aforementioned meta-analysis ${ }^{(33)}$, the prudent/healthy dietary pattern, rich in intakes of vegetables, leafy vegetables, legumes and fish, was associated to decreased $\mathrm{BC}$ risk (relative risk comparing top $v$. bottom categories $=0 \cdot 89,95 \%$ CI $0 \cdot 82,0 \cdot 99)$, while the Western/ 
Table 4 Hazard ratios (HR) and $95 \%$ confidence intervals for breast cancer (BC) by quintiles of pattern scores (first and second components of treelet transform, cut-level 16) for overall, oestrogen receptor-positive $\left(E R^{+}\right)$and oestrogen receptor-negative (ER $\left.{ }^{-}\right)$tumours in 334850 women in the European Prospective Investigation into Cancer and Nutrition (EPIC)

\begin{tabular}{|c|c|c|c|c|c|c|c|c|c|c|c|c|}
\hline \multirow[b]{2}{*}{ Model* $^{*}$} & \multicolumn{6}{|c|}{ TC1 } & \multicolumn{6}{|c|}{ TC2 } \\
\hline & $\begin{array}{c}\text { Person- } \\
\text { years }\end{array}$ & $\begin{array}{c}\text { No. of } B C \\
\text { cases }\end{array}$ & $\mathrm{HR}$ & $95 \% \mathrm{Cl}$ & $P_{\mathrm{LRT}} \dagger$ & $P_{\text {trend }} \ddagger$ & $\begin{array}{c}\text { Person- } \\
\text { years }\end{array}$ & $\begin{array}{c}\text { No. of } B C \\
\text { cases }\end{array}$ & $\mathrm{HR}$ & $95 \% \mathrm{Cl}$ & $P_{\text {LRT }} \dagger$ & $P_{\text {trend }} \neq$ \\
\hline \multicolumn{13}{|l|}{ Overall } \\
\hline Q1 & 730785 & 1784 & 1.00 & Ref. & 0.39 & 0.36 & 747690 & 2317 & 1.00 & Ref. & 0.02 & $<0.001$ \\
\hline Q2 & 738136 & 2342 & 1.06 & $0.99,1.13$ & & & 736718 & 2307 & 0.95 & $0.89,1.00$ & & \\
\hline Q3 & 735683 & 2376 & 1.04 & $0.97,1.11$ & & & 729544 & 2365 & 0.95 & $0.89,1.01$ & & \\
\hline Q4 & 737533 & 2513 & 1.06 & $0.99,1.14$ & & & 725903 & 2350 & 0.94 & $0.88,1.00$ & & \\
\hline Q5 & 728303 & 2561 & 1.05 & $0.98,1.13$ & & & 730584 & 2237 & 0.89 & $0.83,0.95$ & & \\
\hline \multicolumn{13}{|l|}{$\mathrm{ER}^{+}$} \\
\hline Q1 & 725634 & 885 & 1.00 & Ref. & 0.55 & 0.47 & 740268 & 1133 & 1.00 & Ref. & 0.13 & 0.02 \\
\hline Q2 & 731571 & 1214 & 1.07 & $0.98,1.17$ & & & 729915 & 1140 & 0.92 & $0.84,1.00$ & & \\
\hline Q3 & 728782 & 1212 & 1.06 & $0.97,1.16$ & & & 722467 & 1192 & 0.92 & $0.84,1.00$ & & \\
\hline Q4 & 729703 & 1247 & 1.08 & $0.98,1.19$ & & & 719201 & 1193 & 0.90 & $0.83,0.99$ & & \\
\hline Q5 & 720422 & 1272 & 1.05 & $0.95,1.16$ & & & 724261 & 1172 & 0.89 & $0.81,0.98$ & & \\
\hline \multicolumn{13}{|l|}{$\mathrm{ER}^{-}$} \\
\hline Q1 & 721118 & 227 & 1.00 & Ref. & 0.94 & 0.43 & 734469 & 287 & 1.00 & Ref. & 0.25 & 0.06 \\
\hline Q2 & 725180 & 302 & 1.03 & $0.86,1.23$ & & & 724168 & 318 & 1.06 & $0.90,1.24$ & & \\
\hline Q3 & 722496 & 301 & 0.99 & $0.82,1.18$ & & & 716332 & 288 & 0.93 & $0.78,1 \cdot 10$ & & \\
\hline Q4 & 723410 & 316 & 1.01 & $0.83,1.22$ & & & 713221 & 288 & 0.93 & $0.78,1.12$ & & \\
\hline Q5 & 714166 & 292 & 0.95 & $0.78,1.16$ & & & 718180 & 257 & 0.87 & $0.71,1.05$ & \multirow{2}{*}{\multicolumn{2}{|c|}{0.12}} \\
\hline$P_{\text {heterogeneity }} \S$ & & & & & \multicolumn{2}{|c|}{0.70} & & & & & & \\
\hline
\end{tabular}

TC1, treelet component 1; TC2, treelet component 2; Q1, quintile 1; Q2, quintile 2; Q3, quintile 3; Q4, quintile 4; Q5, quintile 5; Ref., reference category. *Models were stratified by study centre and age in 1-year categories and adjusted for baseline menopausal status (premenopausal and perimenopausal (reference) or postmenopausal and women who underwent an ovariectomy), baseline alcohol intake (never drinkers (reference), former drinkers, drinkers only at recruitment, lifetime drinkers, unknown), height (continuous), BMI (below (reference) or above $25 \mathrm{~kg} / \mathrm{m}^{2}$ ), schooling level (none, primary (reference), technical/ professional/secondary, longer education, unknown/unspecified), age at first full-term pregnancy (nulliparous (reference), $\leq 21$ years, $21-30$ years, $>30$ years, unknown or missing), age at menarche ( $\leq 12$ years (reference), $12-14$ years, $>14$ years, missing), age at menopause ( $\leq 50$ years (reference), $>50$ years, premenopause or missing), use of hormone replacement therapy (never (reference), ever, unknown), level of physical activity (inactive (reference), moderately inactive, moderately active, active, unknown) and alcohol-free energy (continuous).

$\dagger P_{\text {LRT }}, P$ values for the likelihood ratio test (LRT) that was used to evaluate the overall significance of a score variable in quintile categories compared with a $X^{2}$ distribution with $\mathrm{df}=4$.

$\ddagger P_{\text {trend }}, P$ values obtained by modelling score variables with quintile-specific medians as continuous variables.

$\S P_{\text {heterogeneity, }} P$ values for $\mathrm{BC}$ risks across ER status with $\mathrm{df}=1$ obtained using a data augmentation method.

unhealthy pattern, characterized by intakes of high-fat dairy products, red meat, processed meats and French fries, was not associated with $\mathrm{BC}$ risk. A recent study of the California Teachers Cohort identified a plant-based pattern, which was related to a reduction of $\mathrm{BC}$ risk $^{(67)}$. In parallel, increasing evidence is accumulating that adherence to the a priori defined Mediterranean pattern is associated with a decreased $\mathrm{BC}$ risk $^{(68-70)}$, although results from these studies are not totally consistent, particularly for premenopausal women ${ }^{(70,71)}$.

The dimension reduction techniques used herein were applied to nutrient densities. Nutrients are present in different combinations of foods, are less country-specific and are directly involved in biological reactions ${ }^{(72)}$. By exploring macro- and micronutrients, the present study aimed to provide an exhaustive representation of individuals' diet. Log-transformation was used to address scaling issues that can arise because macro- and micronutrients are expressed in different units. In this way, the variance and the components' decomposition are invariant to the unit of measure. Dietary normalization was achieved using equal energy, i.e. by dividing nutrient intakes by energy intake, minus energy from alcohol intake ${ }^{(44)}$. Most nutrients are associated with total energy because either they contribute to total energy directly or because people with higher energy values tend to display larger intakes of specific nutrients ${ }^{(44,73)}$.

The first two patterns were retained as they were the most interpretable and depicted realistic nutrient patterns that could ultimately be linked with disease risk. The first pattern identified a diet characterized by animal products as opposed to a vegetarian diet, and was associated with a non-significant increase of $5 \%$ in BC risk (TT). TC1 was quite comparable to a Western pattern. Two recent reviews on dietary patterns and $\mathrm{BC}^{(74,75)}$ showed that diets rich in high-fat foods and processed meats were associated with an increased BC risk, although the findings described in both reviews have not been conclusive in this respect with most results reporting a positive association between Western-like dietary pattern and $\mathrm{BC}$ being not statistically significant ${ }^{(74,75)}$. In our study, the micronutrient-dense pattern characterized by a diet rich in vitamins and minerals, akin to a prudent pattern, was associated with an $11 \%$ reduction in $\mathrm{BC}$ risk (TT), in line with previous findings ${ }^{(33,74,75)}$. The protective effect may come from the anti-carcinogenic properties of nutrients such as $\beta$-carotene, vitamins $\mathrm{C}$ and $\mathrm{E}$, that may exert an antioxidant effect on oestrogen metabolism and reduce cell proliferation ${ }^{(75)}$. The TT components were 

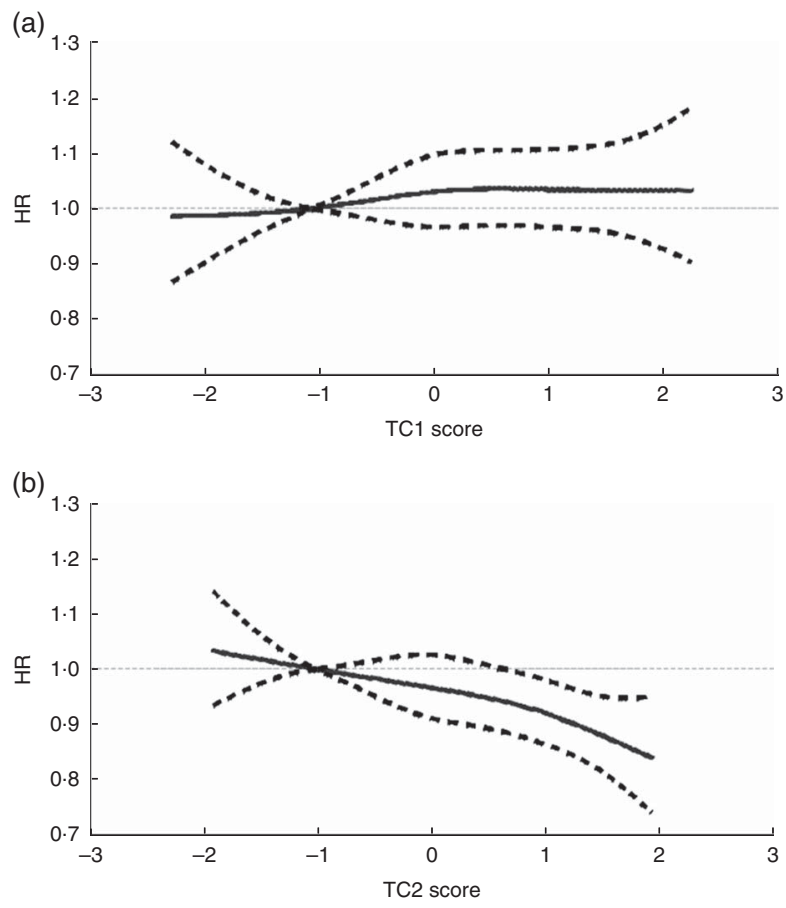

Fig. 2 Relationship between nutrient patterns derived from treelet transform and breast cancer risk (- hazard ratio (HR); - - - - , associated $95 \% \mathrm{Cl}$ ), obtained by using restrictive cubic splines with values of 1 st and 99th percentiles and medians of quintiles 1, 3 and 5 used as knots, among 334850 women in the European Prospective Investigation into Cancer and Nutrition (EPIC): (a) first treelet component (TC1), $P_{\text {non- }}$ linearity $=0.94, P_{\text {trend }}=0.88$; (b) second treelet component (TC2), $P_{\text {non-linearity }}=0.77, P_{\text {trend }}=0.02$. Models were stratified by study centre and age in 1-year categories and adjusted for baseline menopausal status (premenopausal and perimenopausal (reference) or postmenopausal and women who underwent an ovariectomy), baseline alcohol intake (never drinkers (reference), former drinkers, drinkers only at recruitment, lifetime drinkers, unknown), height (continuous), BMI (below (reference) or above $25 \mathrm{~kg} / \mathrm{m}^{2}$ ), schooling level (none, primary (reference), technical/ professional/secondary, longer education, unknown/unspecified), age at first full-term pregnancy (nulliparous (reference), $\leq 21$ years, 21-30 years, $>30$ years, unknown or missing), age at menarche ( $\leq 12$ years (reference), 12-14 years, $>14$ years, missing), age at menopause ( $\leq 50$ years (reference), $>50$ years, pre-menopause or missing), use of hormone replacement therapy (never (reference), ever, unknown), level of physical activity (inactive (reference), moderately inactive, moderately active, active, unknown) and alcohol-free energy (continuous). $P_{\text {trend }}$ was obtained by evaluating the joint significance of variables other than the linear one in the model by using Wald's test with $d f=3$

highly correlated with those of PCA $\left(\rho_{\mathrm{TC} 1, \mathrm{PC} 1}=0 \cdot 91, \rho_{\mathrm{TC} 2}\right.$, $\mathrm{PC}_{2}=0.86$ ). TT and PCA provided overall consistent findings in terms of pattern identification and amount of total variability explained. Further analyses were conducted by menopausal status at cohort enrolment, showing no differential association in pre- and postmenopausal women. Analyses carried out by hormonal receptor status showed that the second TT nutrient pattern was related to a significant decrease in $\mathrm{BC}$ risk for $\mathrm{ER}^{+}, \mathrm{PR}^{+}, \mathrm{PR}^{-}$and $\mathrm{ER}^{+} / \mathrm{PR}^{+}$ tumours. These results are complementary to previous literature findings on dietary patterns and hormonal defined risk of $\mathrm{BC}^{(58,67,70,75)}$. Indeed, Fung et al. found that a prudent dietary pattern was linked with decreased $\mathrm{ER}^{-}$risk (relative risk $=0 \cdot 62,95 \% \mathrm{CI} 0 \cdot 45,0 \cdot 91)^{(76)} \cdot \mathrm{ER}^{-} / \mathrm{PR}^{-}$tumour risk was reduced in postmenopausal women among participants in the highest quintiles of a plant-based pattern and an a priori defined Mediterranean diet by $34 \%$ and $20 \%$, respectively ${ }^{(67,70)}$. Results from the Pooling Project of Prospective Studies of Diet and Cancer found a protective association between total fruit or fruit and vegetable consumption in $\mathrm{ER}^{-}$tumours but not in $\mathrm{ER}^{+}$tumours or overall $\mathrm{BC}$ risk ${ }^{(77)}$.

Whereas a large portion of the scientific literature on dietary patterns has used factor analysis or principal component factor analysis ${ }^{(74)}$, the current paper promotes the use of TT. While PCA produces patterns that are eigenvectors of a covariance/correlation matrix of starting variables, TT is a multivariate technique that yields components by aggregating variables according to covariance/correlation $^{(78)}$, while at the same time exploring the clustering structure of variables, combining features of PCA with those of cluster analysis. Eventually, TT produces a cluster tree revealing the hierarchical grouping structure of variables. The dendrogram allows a visual inspection of the way different nutrients cluster, possibly easing interpretability of patterns. In addition, loadings are sparse, i.e. some of them are equal to zero as they do not pertain to the clustering node of the component so that a limited number of variables contributes to each treelet component.

In line with other clustering techniques ${ }^{(79)}$, TT users are confronted with subjective decisions to select the appropriate cut-level for the cluster tree. Information on the grouping structure of variables that have joined (or not) the tree are specific to each level of the TT tree. By choosing a cut-level, the user decides on how much information to extract and the degree of sparsity of the components. If the tree is cut near the 'root', all nutrient variables join the tree. The information would be comparable to PCA output, i.e. all variables would contribute to treelet components. If the tree is cut closer to the 'leaves', i.e. when the cut-level is lower, loadings are sparse as many are equal to zero, possibly making the interpretation easier. By contrast, this may lead to components that do not capture dietary complexity and are therefore not informative. As pointed out by Meinshausen and Bühlmann, the use of TT leads to a trade-off between amount of variability explained and sparsity. The objective is to 'make the results as sparse as possible but not any sparser ${ }^{\text {(48) }}$. To identify an optimal cut-level, crossvalidation can be used. Once the cut-level is chosen, the loadings computed are invariant to the number of components to be retained; hence keeping $n$ components is an a priori parameter to be specified in the cross-validation step.

The present study relied on dietary questionnaires to assess nutrient intakes, which are prone to measurement errors and may lack information on some relevant nutrients. Questionnaires were country-specific, potentially 
Table 5 Hazard ratios (HR) and $95 \%$ confidence intervals for breast cancer (BC) by quintiles of pattern scores (first and second components of treelet transform, cut-level 16) for oestrogen receptor-positive + progesterone receptor-positive $\left(\mathrm{ER}^{+} / \mathrm{PR}^{+}\right)$and oestrogen receptornegative + progesterone receptor-negative $\left(\mathrm{ER}^{-} / \mathrm{PR}^{-}\right)$tumours in 334850 women in the European Prospective Investigation into Cancer and Nutrition (EPIC)

\begin{tabular}{|c|c|c|c|c|c|c|c|c|c|c|c|c|}
\hline \multirow[b]{2}{*}{ Model $^{*}$} & \multicolumn{6}{|c|}{ TC1 } & \multicolumn{6}{|c|}{ TC2 } \\
\hline & $\begin{array}{c}\text { Person- } \\
\text { years }\end{array}$ & $\begin{array}{c}\text { No. of } \mathrm{BC} \\
\text { cases }\end{array}$ & $\mathrm{HR}$ & $95 \% \mathrm{Cl}$ & $P_{\mathrm{LRT}} \dagger$ & $P_{\text {trend }} \ddagger$ & $\begin{array}{c}\text { Person- } \\
\text { years }\end{array}$ & $\begin{array}{c}\text { No. of } \mathrm{BC} \\
\text { cases }\end{array}$ & $\mathrm{HR}$ & $95 \% \mathrm{Cl}$ & $P_{\mathrm{LRT}} \dagger$ & $P_{\text {trend }} \ddagger$ \\
\hline \multicolumn{13}{|l|}{$\mathrm{ER}^{+} / \mathrm{PR}^{+}$} \\
\hline Q1 & 723508 & 568 & 1.00 & Ref. & 0.16 & 0.26 & 737812 & 753 & 1.00 & Ref. & 0.15 & $<0.01$ \\
\hline Q2 & 728884 & 811 & $1 \cdot 15$ & $1.03,1.29$ & & & 727617 & 777 & 0.95 & $0.86,1.05$ & & \\
\hline Q3 & 725948 & 750 & 1.10 & $0.98,1.23$ & & & 719931 & 777 & 0.94 & $0.84,1.04$ & & \\
\hline Q4 & 726667 & 751 & 1.11 & $0.98,1.25$ & & & 716303 & 720 & 0.89 & $0.79,0.99$ & & \\
\hline Q5 & 717569 & 773 & 1.11 & $0.98,1.26$ & & & 720914 & 626 & 0.86 & $0.76,0.98$ & & \\
\hline \multicolumn{13}{|l|}{$\mathrm{ER}^{-} / \mathrm{PR}^{-}$} \\
\hline Q1 & 720830 & 172 & 1.00 & Ref. & 0.60 & 0.31 & 734117 & 218 & 1.00 & Ref. & 0.26 & 0.08 \\
\hline Q2 & 724871 & 235 & 1.09 & $0.89,1.33$ & & & 723844 & 241 & 1.05 & $0.87,1.26$ & & \\
\hline Q3 & 722003 & 207 & 0.93 & $0.75,1.15$ & & & 715963 & 207 & 0.88 & $0.72,1.08$ & & \\
\hline Q4 & 722988 & 222 & 0.98 & $0.79,1.23$ & & & 712804 & 210 & 0.93 & $0.76,1.14$ & & \\
\hline Q5 & 713798 & 214 & 0.97 & $0.77,1.22$ & & & 717762 & 174 & 0.85 & $0.68,1.06$ & & \\
\hline$P_{\text {heterogeneity }} \S$ & & & & & \multicolumn{2}{|c|}{0.19} & & & & & \multicolumn{2}{|c|}{0.27} \\
\hline
\end{tabular}

TC1, treelet component 1; TC2, treelet component 2; Q1, quintile 1; Q2, quintile 2; Q3, quintile 3; Q4, quintile 4; Q5, quintile 5; Ref., reference category. *Models were stratified by study centre and age in 1-year categories and adjusted for baseline menopausal status (premenopausal and perimenopausal (reference) or postmenopausal and women who underwent an ovariectomy), baseline alcohol intake (never drinkers (reference), former drinkers, drinkers only at recruitment, lifetime drinkers, unknown), height (continuous), BMl (below (reference) or above $25 \mathrm{~kg} / \mathrm{m}^{2}$ ), schooling level (none, primary (reference), technical/ professional/secondary, longer education, unknown/unspecified), age at first full-term pregnancy (nulliparous (reference), $\leq 21$ years, $21-30$ years, $>30$ years, unknown or missing), age at menarche ( $\leq 12$ years (reference), $12-14$ years, $>14$ years, missing), age at menopause ( $\leq 50$ years (reference), $>50$ years, premenopause or missing), use of hormone replacement therapy (never (reference), ever, unknown), level of physical activity (inactive (reference), moderately inactive, moderately active, active, unknown) and alcohol-free energy (continuous).

$\dagger P_{\mathrm{LRT}}, P$ values for the likelihood ratio test (LRT) that was used to evaluate the overall significance of a score variable in quintile categories compared with a $\chi^{2}$ distribution with $\mathrm{df}=4$.

$\ddagger P_{\text {trend }}, P$ values obtained by modelling score variables with quintile-specific medians as continuous variables.

$\S P_{\text {heterogeneity }} P$ values for $\mathrm{BC}$ risks across ER/PR status with $\mathrm{df}=1$ obtained using a data augmentation method.

introducing systematic between-country differences in nutrient assessment. However, in the EPIC study, harmonized composition tables across European countries were used to translate food into nutrient intakes ${ }^{(42)}$, thus sizeably improving the comparability of nutrient intakes.

One key element in pattern literature is reproducibility of patterns across populations. With twenty-three centres from ten countries, EPIC accounts for a wide heterogeneity in diet ${ }^{(80,81)}$. Previous findings in Moskal et al.'s study ${ }^{(45)}$ on the EPIC data showed that more than $75 \%$ of the variance that would be captured by centre-specific PC was captured by PC from overall PCA. This evidence suggested that overall PCA combining data from all EPIC centres allows capturing a good proportion of the variance explained by each EPIC centre. This motivated the choice of applying pattern decomposition on the overall data.

\section{Conclusion}

The current study presented results of a nutrient pattern analysis in an international setting using a new tool, TT, and subsequently related the patterns to risk of developing BC. TT is a complementary method to PCA in nutritional epidemiology as it produces readily interpretable sparse components. In the EPIC study, nutrient patterns characterized by a diet rich in macronutrients of animal origin, such as cholesterol or SFA, were associated with a non-significant increase in $\mathrm{BC}$ risk while a diet rich in vitamins, minerals and $\beta$-carotene, indicating a more plant-based diet, was associated with a significant decreased BC risk. This decrease was also significant for $\mathrm{ER}^{+}, \mathrm{PR}^{+}, \mathrm{PR}^{-}$and $\mathrm{ER}^{+} / \mathrm{PR}^{+}$ tumours.

\section{Acknowledgements}

Acknowledgement: The authors thank Dr Anders GorstRasmussen (Department of Cardiology, Aalborg University Hospital) for his critical input and useful discussions about the manuscript. Financial support: The coordination of the EPIC study is financially supported by the European Commission (Directorate General for Health and Consumer Affairs) and the International Agency for Research on Cancer (IARC). The national cohorts are supported by: the Health Research Fund (FIS) of the Spanish Ministry of Health RTICC 'Red Temática de Investigación Cooperativa en Cáncer (grant numbers Rd06/0020/0091 and Rd12/0036/0018), the Regional Governments of Andalucía, Asturias, Basque Country, Murcia (project 6236) and Navarra, and the Instituto de Salud Carlos III, Redes de Investigacion Cooperativa (RD06/0020) (Spain); the Danish Cancer Society (Denmark); the Ligue Contre le Cancer, the Institut Gustave Roussy, Mutuelle Générale de l'Education Nationale and the Institut National 
de la Santé et de la Recherche Médicale (France); the Deutsche Krebshilfe, the Deutsches Krebsforschungszentrum and the Federal Ministry of Education and Research (Germany); the Hellenic Health Foundation, the Stavros Niarchos Foundation and the Hellenic Ministry of Health and Social Solidarity (Greece); the Italian Association for Research on Cancer (AIRC) and the National Research Council (Italy); the Dutch Ministry of Public Health, Welfare and Sports, the Netherlands Cancer Registry, LK Research Funds, Dutch Prevention Funds, Dutch Zorg Onderzoek Nederland, the World Cancer Research Fund and Statistics Netherlands (Netherlands); the European Research Council (2009-AdG 232997) and the Nordforsk, Nordic Centre of Excellence programme on Food, Nutrition and Health (Norway); the Swedish Cancer Society, the Swedish Research Council and the Regional Governments of Skåne and Västerbotten (Sweden); Cancer Research UK, the Medical Research Council, the Stroke Association, the British Heart Foundation, the Department of Health, the Food Standards Agency and the Wellcome Trust (UK). The work undertaken by N.A. was supported by a Université de Lyon doctoral grant (EDISS doctoral school). Conflict of interest: None. Authorship: The authors' responsibilities were as follows. N.A. performed statistical analyses; N.A. and P.F. interpreted the findings and developed a first draft of the manuscript; A.M., N.S., V.V., V.C., H.F., S.M., S.K., J.F., E.W., L.L.-B. and I.R. contributed to the writing of the manuscript; P.A., E.A., E.M.-M., D.S., J.R.Q., A.O., A.Tj., C.C.D., K.O., L.D., A.F., L.B., R.T.F., R.K., A.Tr., C.B., P.O., M.S.D.M., G.M., C.A., F.R., R.Tu., H.B.B.d.M., M.F.B., P.H.M.P., G.S., T.B., A.W., I.J., K.-T.K., N.J.W., T.K., R.Tr., J.A.S., M.A.M. and E.R. substantially contributed to the interpretation of results and critically revised the content of the manuscript; and all authors contributed to the planning, execution and interpretation of the submitted manuscript, and read and approved the final manuscript. Ethics of buman subject participation: This study was conducted according to the guidelines laid down in the Declaration of Helsinki and all procedures involving human subjects were approved by the IARC and the local ethical review committees. Written informed consent was obtained from all participants.

\section{Supplementary material}

To view supplementary material for this article, please visit http://dx.doi.org/10.1017/S1368980015000294

\section{References}

1. Bray F, Ren JS, Masuyer E et al. (2013) Estimates of global cancer prevalence for 27 sites in the adult population in 2008. Int J Cancer 132, 1133-1145.

2. Key TJ, Verkasalo PK \& Banks E (2001) Epidemiology of breast cancer. Lancet Oncol 2, 133-140.

3. Collaborative Group on Hormonal Factors in Breast Cancer (2001) Familial breast cancer: collaborative reanalysis of individual data from 52 epidemiological studies including
58209 women with breast cancer and 101986 women without the disease. Lancet 358, 1389-1399.

4. Green J, Cairns BJ, Casabonne D et al. (2011) Height and cancer incidence in the Million Women Study: prospective cohort, and meta-analysis of prospective studies of height and total cancer risk. Lancet Oncol 12, 785-794.

5. Chlebowski R (2007) Lifestyle change including dietary fat reduction and breast cancer outcome. J Nutr 137, 1 Suppl., 233S-235S.

6. Anothaisintawee $\mathrm{T}$, Wiratkapun $\mathrm{C}$, Lerdsitthichai $\mathrm{P}$ et al. (2013) Risk factors of breast cancer: a systematic review and meta-analysis. Asia Pac J Public Health 25, 368-387.

7. McKenzie F, Ellison-Loschmann L, Jeffreys M et al. (2013) Cigarette smoking and risk of breast cancer in a New Zealand multi-ethnic case-control study. PLoS One 8, e63132.

8. Terry PD \& Goodman M (2006) Is the association between cigarette smoking and breast cancer modified by genotype? A review of epidemiologic studies and meta-analysis. Cancer Epidemiol Biomarkers Prev 15, 602-611.

9. Rohan TE, Heo M, Choi L et al. (2013) Body fat and breast cancer risk in postmenopausal women: a longitudinal study. J Cancer Epidemiol 2013, 754815.

10. McCullough LE, Eng SM, Bradshaw PT et al. (2012) Fat or fit: the joint effects of physical activity, weight gain, and body size on breast cancer risk. Cancer 118, 4860-4568.

11. Amadou A, Hainaut P \& Romieu I (2013) Role of obesity in the risk of breast cancer: lessons from anthropometry. J Oncol 2013, 906495.

12. World Cancer Research Fund/American Institute for Cancer Research (2010) Continuous Update Project Report. Food, Nutrition, Physical Activity, and the Prevention of Breast Cancer. http://www.dietandcancerreport.org/cancer_resource_ center/downloads/cu/Breast-Cancer-2010-Report.pdf

13. Monninkhof EM, Elias SG, Vlems FA et al. (2007) Physical activity and breast cancer: a systematic review. Epidemiology 18, 137-157.

14. Fagherazzi G, Vilier A, Boutron-Ruault M-C et al. (2014) Alcohol consumption and breast cancer risk subtypes in the E3N-EPIC cohort. Eur J Cancer Prev (Epublication ahead of print version).

15. Tjønneland A, Christensen J, Olsen A et al. (2007) Alcohol intake and breast cancer risk: the European Prospective Investigation into Cancer and Nutrition (EPIC). Cancer Causes Control 18, 361-373.

16. Zhang SM, Lee I-M, Manson JE et al. (2007) Alcohol consumption and breast cancer risk in the Women's Health Study. Am J Epidemiol 165, 667-676.

17. Cui X, Dai Q, Tseng M et al. (2007) Dietary patterns and breast cancer risk in the Shanghai breast cancer study. Cancer Epidemiol Biomarkers Prev 16, 1443-1448.

18. Levi F, Pasche C, Lucchini F et al. (2001) Dietary intake of selected nutrients and breast-cancer risk. Int J Cancer $\mathbf{9 1}$, 260-263.

19. Doll R (1992) The lessons of life: keynote address to the nutrition and cancer conference. Cancer Res 52, 7 Suppl., 2024S-2029S.

20. Anand $\mathrm{P}$, Kunnumakkara $\mathrm{AB}$, Kunnumakara $\mathrm{AB}$ et al. (2008) Cancer is a preventable disease that requires major lifestyle changes. Pharm Res 25, 2097-2116.

21. Ferrari P, Rinaldi S, Jenab M et al. (2013) Dietary fiber intake and risk of hormonal receptor-defined breast cancer in the European Prospective Investigation into Cancer and Nutrition study. Am J Clin Nutr 97, 344-353.

22. Wu AH, Yu MC, Tseng C-C et al. (2003) Green tea and risk of breast cancer in Asian Americans. Int J Cancer 106, 574-579.

23. Shrubsole MJ, Jin F, Dai Q et al. (2001) Dietary folate intake and breast cancer risk: results from the Shanghai Breast Cancer Study. Cancer Res 61, 7136-7141. 
24. Jacques PF \& Tucker KL (2001) Are dietary patterns useful for understanding the role of diet in chronic diseases? $\mathrm{Am} \mathrm{J}$ Clin Nutr 73, 1-2.

25. Hu FB (2002) Dietary pattern analysis: a new direction in nutritional epidemiology. Curr Opin Lipidol 13, 3-9.

26. Jacobs DR \& Steffen LM (2003) Nutrients, foods, and dietary patterns as exposures in research: a framework for food synergy. Am J Clin Nutr 78, 3 Suppl., 508S-513S.

27. De Stefani E, Deneo-Pellegrini H, Boffetta P et al. (2009) Dietary patterns and risk of cancer: a factor analysis in Uruguay. Int J Cancer 124, 1391-1397.

28. Edefonti V, Bravi F, Garavello W et al. (2010) Nutrient-based dietary patterns and laryngeal cancer: evidence from an exploratory factor analysis. Cancer Epidemiol Biomarkers Prev 19, 18-27.

29. Nkondjock A, Krewski D, Johnson KC et al. (2005) Dietary patterns and risk of pancreatic cancer. Int J Cancer 114, 817-823.

30. Schulze MB, Hoffmann K, Kroke A et al. (2001) Dietary patterns and their association with food and nutrient intake in the European Prospective Investigation into Cancer and Nutrition (EPIC)-Potsdam study. Br J Nutr 85, 363-373.

31. Vrieling A, Buck K, Seibold P et al. (2013) Dietary patterns and survival in German postmenopausal breast cancer survivors. Br J Cancer 108, 188-192.

32. De Stefani E, Boffetta P, Ronco AL et al. (2008) Nutrient patterns and risk of lung cancer: a factor analysis in Uruguayan men. Lung Cancer 61, 283-291.

33. Brennan SF, Cantwell MM, Cardwell CR et al. (2010) Dietary patterns and breast cancer risk: a systematic review and meta-analysis. Am J Clin Nutr 91, 1294-1302.

34. Dahm CC, Gorst-Rasmussen A, Crowe FL et al. (2012) Fatty acid patterns and risk of prostate cancer in a case-control study nested within the European Prospective Investigation into Cancer and Nutrition. Am J Clin Nutr 96, 1354-1361.

35. Gorst-Rasmussen A, Dahm CC, Dethlefsen C et al. (2011) Exploring dietary patterns by using the treelet transform. $\mathrm{Am}$ $J$ Epidemiol 173, 1097-1104.

36. Schoenaker DAJM Dobson AJ, Soedamah-Muthu SS et al. (2013) Factor analysis is more appropriate to identify overall dietary patterns associated with diabetes when compared with Treelet transform analysis. J Nutr 143, 392-398.

37. Jolliffe IT (2002) Principal Component Analysis, 2nd ed. New York: Springer-Verlag.

38. Riboli E, Hunt KJ, Slimani N et al. (2002) European Prospective Investigation into Cancer and Nutrition (EPIC): study populations and data collection. Public Health Nutr $\mathbf{5}$, $1113-1124$

39. Riboli E \& Kaaks R (1997) The EPIC project: rationale and study design. European Prospective Investigation into Cancer and Nutrition. Int J Epidemiol 26, Suppl. 1, S6-S14.

40. Kaaks R, Slimani N \& Riboli E (1997) Pilot phase studies on the accuracy of dietary intake measurements in the EPIC project: overall evaluation of results. European Prospective Investigation into Cancer and Nutrition. Int J Epidemiol 26 , Suppl. 1, S26-S36.

41. Margetts B \& Pietinen P (1997) European Prospective Investigation into Cancer and Nutrition: validity studies on dietary assessment methods. Int J Epidemiol 26, Suppl. 1, S1-S5.

42. Slimani N, Deharveng G, Unwin I et al. (2007) The EPIC nutrient database project (ENDB): a first attempt to standardize nutrient databases across the 10 European countries participating in the EPIC study. Eur J Clin Nutr 61, 1037-1056.

43. Bouckaert KP, Slimani N, Nicolas G et al. (2011) Critical evaluation of folate data in European and international databases: recommendations for standardization in international nutritional studies. Mol Nutr Food Res 55, 166-180.

44. Willett WC, Howe GR \& Kushi LH (1997) Adjustment for total energy intake in epidemiologic studies. Am J Clin Nutr 65, 4 Suppl., 1220S-1228S.
45. Moskal A, Pisa P, Ferrari P et al. (2014) Nutrient patterns and their food sources in an international study setting: report from the EPIC study. PLoS One 9, e98647.

46. Imamura F, Lichtenstein AH, Dallal GE et al. (2009) Confounding by dietary patterns of the inverse association between alcohol consumption and type 2 diabetes risk. $\mathrm{Am}$ J Epidemiol 170, 37-45.

47. Gorst-Rasmussen A (2011) tt: treelet transform with Stata. Stata J 12, 130-146.

48. Meinshausen N \& Bühlmann P (2008) Discussion of: treelets - an adaptive multi-scale basis for sparse unordered data. Ann Appl Stat 2, 478-481.

49. Thiébaut ACM \& Bénichou J (2004) Choice of time-scale in Cox's model analysis of epidemiologic cohort data: a simulation study. Stat Med 23, 3803-3820.

50. Ferrari P, Day NE, Boshuizen HC et al. (2008) The evaluation of the diet/disease relation in the EPIC study: considerations for the calibration and the disease models. Int J Epidemiol 37, 368-378.

51. Lunn M \& McNeil D (1995) Applying Cox regression to competing risks. Biometrics 51, 524-532.

52. Heinzel H \& Kaider A (1997) Gaining more flexibility in Cox proportional hazards regression models with cubic spline functions. Comput Methods Programs Biomed 54, 201-208.

53. Männistö S, Dixon LB, Balder HF et al. (2005) Dietary patterns and breast cancer risk: results from three cohort studies in the DIETSCAN project. Cancer Causes Control 16, $725-733$.

54. Agurs-Collins T, Rosenberg L, Makambi K et al. (2009) Dietary patterns and breast cancer risk in women participating in the Black Women's Health Study. Am J Clin Nutr 90, 621-628.

55. Terry P, Suzuki R \& Hu FB (2001) A prospective study of major dietary patterns and the risk of breast cancer. Cancer Epidemiol Biomarkers Prev 10, 1281-1285.

56. Sieri S, Krogh V, Pala V et al. (2004) Dietary patterns and risk of breast cancer in the ORDET Cohort. Cancer Epidemiol Biomarkers Prev 13, 567-572.

57. Adebamowo CA, Hu FB, Cho E et al. (2005) Dietary patterns and the risk of breast cancer. Ann Epidemiol 15, 789-795.

58. Fung TT, Hu FB, Holmes MD et al. (2005) Dietary patterns and the risk of postmenopausal breast cancer. Int J Cancer 116, 116-121.

59. Nkondjock A \& Ghadirian P (2005) Associated nutritional risk of breast and colon cancers: a population-based case-control study in Montreal, Canada. Cancer Lett 223 , 85-91.

60. Velie EM, Schairer C, Flood A et al. (2005) Empirically derived dietary patterns and risk of postmenopausal breast cancer in a large prospective cohort study. Am J Clin Nutr 82, 1308-1319.

61. Hirose K, Matsuo K, Iwata H et al. (2007) Dietary patterns and the risk of breast cancer in Japanese women. Cancer Sci 98, 1431-1438.

62. Murtaugh MA, Sweeney C, Giuliano AR et al. (2008) Diet patterns and breast cancer risk in Hispanic and nonHispanic white women: the Four-Corners Breast Cancer Study. Am J Clin Nutr 87, 978-984.

63. Wu AH, Yu MC, Tseng C et al. (2009) Dietary patterns and breast cancer risk in Asian American women. Am J Clin Nutr 89, $1145-1154$

64. Cottet V, Touvier M, Fournier A et al. (2009) Postmenopausal breast cancer risk and dietary patterns in the E3N-EPIC prospective cohort study. Am J Epidemiol 170, $1257-1267$.

65. Ronco AL, de Stefani E, Aune D et al. (2010) Nutrient patterns and risk of breast cancer in Uruguay. Asian Pac J Cancer Prev 11, 519-524. 
66. Edefonti V, Decarli A, La Vecchia C et al. (2008) Nutrient dietary patterns and the risk of breast and ovarian cancers. Int J Cancer 122, 609-613.

67. Link LB, Canchola AJ, Bernstein L et al. (2013) Dietary patterns and breast cancer risk in the California Teachers Study cohort. Am J Clin Nutr 98, 1524-1532.

68. Trichopoulou A, Bamia C, Lagiou P et al. (2010) Conformity to traditional Mediterranean diet and breast cancer risk in the Greek EPIC (European Prospective Investigation into Cancer and Nutrition) cohort. Am J Clin Nutr 92, 620-625.

69. Demetriou CA, Hadjisavvas A, Loizidou MA et al. (2012) The Mediterranean dietary pattern and breast cancer risk in GreekCypriot women: a case-control study. BMC Cancer 12, 113.

70. Buckland G, Travier N, Cottet V et al. (2013) Adherence to the Mediterranean diet and risk of breast cancer in the European prospective investigation into cancer and nutrition cohort study. Int J Cancer 132, 2918-2927.

71. Couto E, Sandin S, Lo M et al. (2013) Mediterranean dietary pattern and risk of breast cancer. PLoS One 8, e 55374 .

72. Edefonti V, Hashibe M, Ambrogi F et al. (2012) Nutrient-based dietary patterns and the risk of head and neck cancer: a pooled analysis in the International Head and Neck Cancer Epidemiology consortium. Ann Oncol 23, 1869-1880.

73. Freedman LS, Hartman AM, Kipnis V et al. (1997) Comments on: adjustment for total energy intake in epidemiologic studies. Am J Clin Nutr 65, 1229-1231.
74. Edefonti V, Randi G, La Vecchia C et al. (2009) Dietary patterns and breast cancer: a review with focus on methodological issues. Nutr Rev 67, 297-314.

75. Albuquerque RCR, Baltar VT \& Marchioni DML (2014) Breast cancer and dietary patterns: a systematic review. Nutr Rev 72, 1-17.

76. Fung TT, Rimm EB, Spiegelman D et al. (2001) Association between dietary patterns and plasma biomarkers of obesity and cardiovascular disease risk. Am J Clin Nutr $\mathbf{7 3}$, 61-67.

77. Jung S, Spiegelman D, Baglietto L et al. (2013) Fruit and vegetable intake and risk of breast cancer by hormone receptor status. J Natl Cancer Inst 105, 219-236.

78. Gorst-Rasmussen A, Dahm CC, Dethlefsen C et al. (2011) Gorst-Rasmussen et al. respond to 'Dietary pattern analysis'. Am J Epidemiol 173, 1109-1110.

79. Krzanowski WJ (2000) Principles of Multivariate Analysis: A User's Perpective, 2nd ed. New York: Oxford University Press Inc.

80. Freisling H, Fahey MT, Moskal A et al. (2010) Regionspecific nutrient intake patterns exhibit a geographical gradient within and between European countries. J Nutr 140, 1280-1286.

81. Slimani N \& Margetts B (2009) Nutrient intakes and patterns in the EPIC cohorts from 10 European countries. Eur J Clin Nutr 63, Suppl. 4, S1-S274. 